\title{
Three-dimensional reconstruction of colon carcinoma metastases in liver
}

\author{
P. GRIFFINI, ${ }^{*} \dagger$ S. M. SMORENBURG, ${ }^{*}$ F. J. VERBEEK $\$ \&$ C. J. F. VAN NOORDEN* \\ *Academic Medical Centre, University of Amsterdam, Department of Cell Biology \& Histology, \\ PO Box 22700, 1100 DE Amsterdam, The Netherlands \\ $\dagger$ Department of Animal Biology and CNR Centre for Histochemistry, University of Pavia, \\ Piazza Botta 10, Italy \\ $\ddagger$ Utrecht Graduate School of Developmental Biology, Hubrecht Laboratory, Uppsalalaan 8 , \\ Utrecht, The Netherlands
}

Key words. 3D reconstruction, basement membrane, Glisson's capsule, metastasis, stroma.

\section{Summary}

Resection of liver metastases in patients with colon cancer increases survival but success depends on removal of all tumour tissue. For this purpose, understanding of spatial relationships between metastases and liver architecture is essential. Because metastatic cancer growth is essentially a three-dimensional (3D) event, we decided to apply 3D reconstruction techniques to study these spatial relationships between metastases and liver structures such as blood vessels, stroma and the liver capsule (Glisson's capsule). Colon carcinoma metastases were experimentally induced in rat liver by injection of colon cancer cells (CC531) into the portal vein. Three weeks later, livers from these animals and control livers were removed and immediately frozen in liquid nitrogen. Thirty-seven to 110 consecutive sections were used for each 3D reconstruction of 26 metastases in eight livers. Contours of different structures were stained by (immuno)histochemical means, traced in each section and stored in a database. From the contour model, a volume model was generated. Among the 26 metastases, seven were found to grow distantly from the liver capsule. They were small and consisted of well-differentiated cancer cells that were totally surrounded by a basement membrane and stroma which was always connected with adjacent blood vessels of a portal tract. The remaining 19 metastases showed a more advanced pattern of development. Infiltration of poorly differentiated colon cancer cells progressed through the stroma at various sites and areas of direct contact between cancer cells and hepatocytes were frequently found. This type of outgrowth of cancer cells

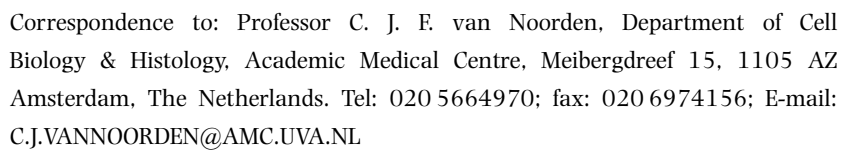

was only found when metastases had made contact with the liver capsule. However, some areas in sections of these advanced stages still resembled small metastases. On the basis of these findings, we conclude that stroma affects the differentiation pattern of cancer cells and has at least a dual role in tumour growth. On the one hand it limits invasion of cancer cells in the surrounding host tissue. On the other hand, stroma formation at the capsule, which consists mainly of granulation tissue, facilitates outgrowth of the tumours. Furthermore, our 3D reconstructions demonstrate the spatial heterogeneity of larger metastases and the importance of a 3D approach to understand growth and development of metastases in general and colon cancer metastases in the liver in particular.

\section{Introduction}

Most deaths of patients with colorectal cancers are due to development of liver metastases that are resistant to conventional therapies (Fidler \& Hart, 1982; Wagner et al., 1984; Fidler \& Balch, 1987; Nicolson, 1987). Resection is the most effective treatment available for liver metastases of colorectal carcinomas (Hughes et al., 1988; Minton et al., 1989; Lise et al., 1990). Successful removal of metastases depends on the spatial relationships between metastases and liver architecture (Bennet et al., 1991). In this aspect, three-dimensional (3D) representation of the liver on the basis of magnetic resonance images (MRI) (Bennet et al., 1991) or spiral computer tomography (CT) images (Van Leeuwen et al., 1994, 1995) are useful in preoperative planning and intraoperative guidance of resection of hepatic metastases. Despite resection, metastases in the liver recur frequently (Nitti et al., 1994). Several factors 
Fig. 1. Liver section stained with the lectin UAE-I to demonstrate specifically cancer cells containing a small (arrow) and a larger (arrowheads) metastasis. Scale bar $=$ $200 \mu \mathrm{m}$.

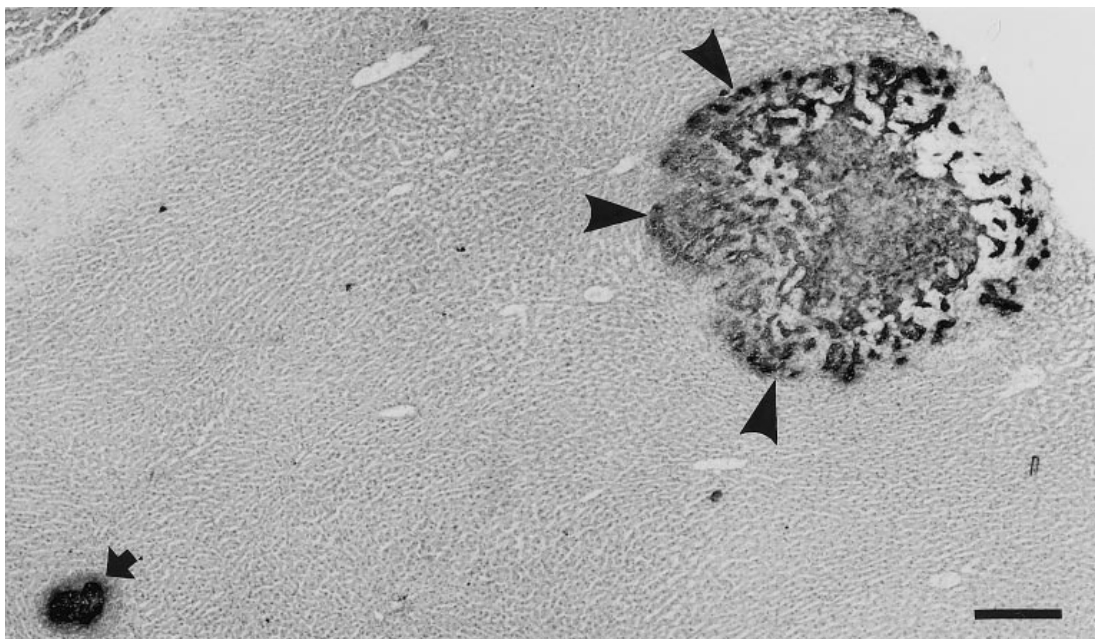

such as resection margins (Fortner et al., 1984; Pedersen et al., 1994), stage of the primary tumour, number of metastases and type of liver resection (Bengmark et al., 1982; Adson et al., 1984; Hughes et al., 1989), hepatectomy and regeneration of the liver as a consequence of the resection (Panis et al., 1992) have been associated with recurrence. Furthermore, resection of metastases is not always possible and/or complete (Pedersen et al., 1994). Therefore, a better understanding of the growth of metastases could be a basis of development of more effective methods for treatment. Invasive growth of tumours is a very complex and dynamic process in vivo and depends upon a variety of interactions between cancer cells and host tissue (Liotta et al., 1991) and on the differentiation grade of cancer cells (Gabbert, 1985; Mareel et al., 1990). So far, studies of development of metastases in liver and the interactions between cancer cells and surrounding tissue and cells were performed on the basis of $2 \mathrm{D}$ observations using tissue sections (e.g. Barberá-Guillem et al., 1989; Dingemans et al., 1994; Griffini et al., 1994, 1996; Smorenburg et al., 1996). It is likely that vital information is lost when the analysis is performed in 2D particularly because tumours are often very heterogeneous. For this reason, we decided to apply 3D reconstruction techniques to obtain 3D images of colon carcinoma metastases in rat liver, in particular for the understanding of spatial relationships between different types of metastases and liver structures such as blood vessels, stroma and the liver capsule (Glisson's capsule). Cancerous growth induces formation of stroma in the host tissue, but relationships between different stages of metastases and stromal reactions are still poorly understood (Nakanishi et al., 1994). For this reason, special attention was given to spatial relationships between cancer cells and stromal cells within the tumours to better understand how stroma affects tumour invasion in the liver.

\section{Materials and methods}

An established colon carcinoma cell line, CC531, was used. The parental cell line was obtained from a 1,2-dimethylhydrazine-induced moderately differentiated and weakly immunogenic colon adenocarcinoma in WAG-Rij rats (Marquet et al., 1984). Cells were cultured at $37^{\circ} \mathrm{C}$ as monolayer in Dulbecco's modification of Eagle's medium (DME; ICN Biomedicals, Irvine, Ayrshire, U.K.) supplemented with $10 \%(\mathrm{v} / \mathrm{v})$ fetal bovine serum, $2 \mathrm{~mm}$ glutamine,

Fig. 2. 3D reconstruction of three colon carcinoma metastases in rat liver. Volume rendering was obtained by applying the ray-casting technique. Encapsulated structures were visualized in two ways: first, by using opacity of the voxels surrounding the structure of interest and second, by using the discontinuity left by the sections that were not imported in the database. These missing sections could have been submitted to an interpolation procedure to render all structures continuous, but we concluded that this would not increase comprehensibility. (A,B) Small metastasis (blue) completely surrounded by stroma (transparent salmon) which was connected with a number of blood vessels (green). There was no contact with the liver capsule. A and B are images from different angles of the same tumour. (C,D) Larger metastasis partly in contact with the liver capsule (yellow) (arrows) and partly unconnected with the liver capsule (arrowheads). In some areas, cancer cells (blue) were surrounded by stroma (transparent salmon) but in several parts of the tumour there was direct contact between cancer cells and hepatocytes (the latter cell type is not visualized). Necrotic areas were not present. C and D are images from different angles of the same tumour. The number of blood vessels in connection with the tumour was low. (E,F) Large metastasis containing a necrotic area (pink) which was in contact with the liver capsule (arrows). Stroma surrounding cancer cells was present in some parts of the tumour only, particularly at the two poles of the tumour (arrowheads) as is shown in F. Not all sections used for the reconstruction were used to visualize clearly the organization of this large tumour. $\mathrm{E}$ and $\mathrm{F}$ are images from different angles of the same tumour. Scale bars $=0.5 \mathrm{~mm}$. 


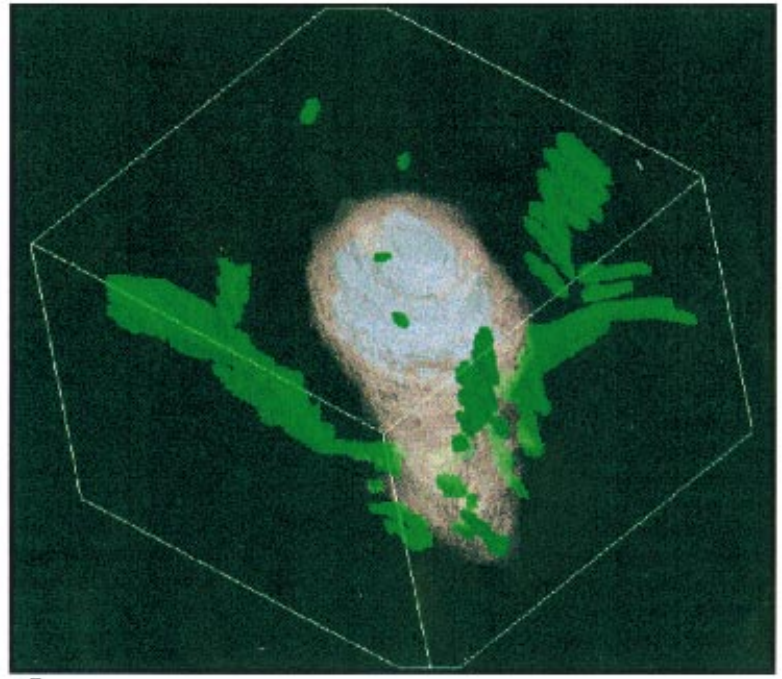

A
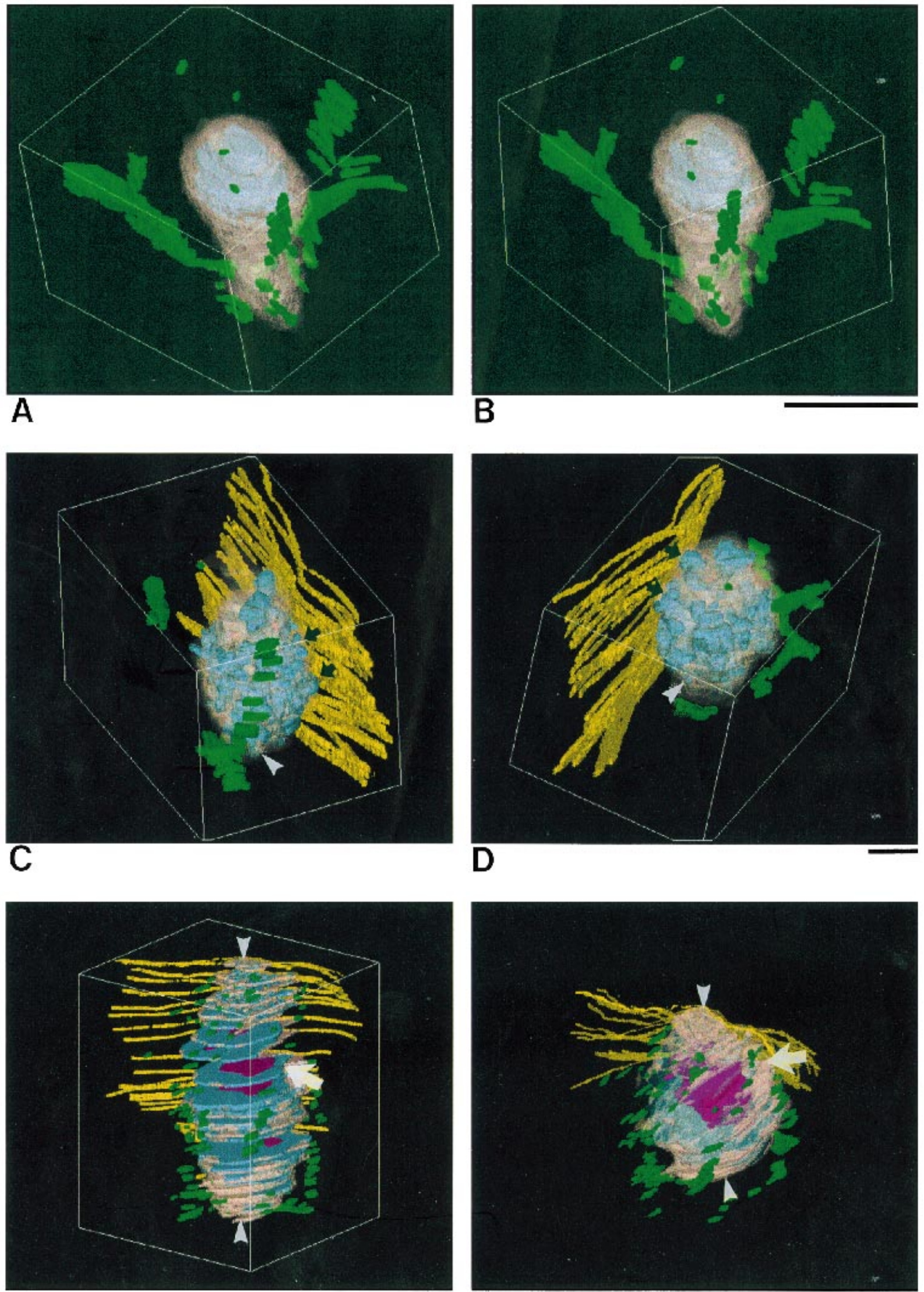

$\mathbf{E}$

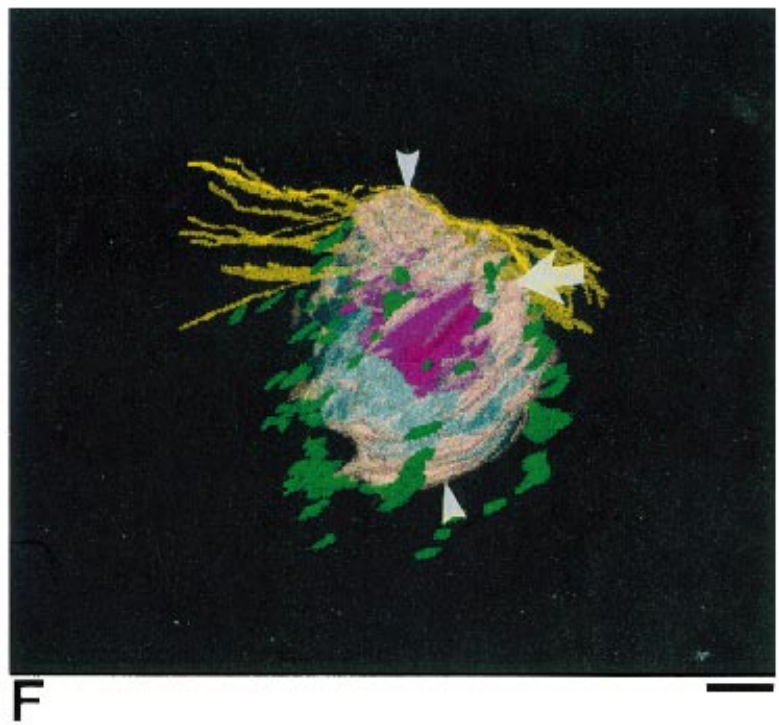

(C) 1997 The Royal Microscopical Society, Journal of Microscopy, 187, 12-21 
$100 \mathrm{IU}$ penicillin $\mathrm{mL}^{-1}$ and $100 \mu \mathrm{g}$ streptomycin $\mathrm{mL}^{-1}$. Colon carcinoma metastases were induced in rat liver by injection of a single cell suspension containing $1 \times 10^{6}$ cancer cells in $0.05 \mathrm{~mL}$ PBS with a $27 \mathrm{G}$ gauge needle through a small midline incision into the portal vein of the liver of eight mature female WAG-Rij rats, weighing 150-170 g, under sodium pentobarbital anaesthesia (Jonges et al., 1993).

The portal vein was closed by treatment of the incision with an aqueous solution of thrombin (Central Laboratory of the Netherlands Red Cross Blood Transfusion Service, Amsterdam, The Netherlands) using a cotton bud.

After 3 weeks, the rats were killed with an overdose of sodium pentobarbital and the livers were removed immediately and cut into small pieces ( $5 \mathrm{~mm}$ thick) to be frozen immediately in liquid nitrogen and stored at $-80^{\circ} \mathrm{C}$ until used. Serial sections ( $8 \mu \mathrm{m}$ thick) were cut at a cabinet temperature of $-25^{\circ} \mathrm{C}$ using a motor-driven Bright cryostat. Sections were picked up onto clean glass slides and stored in the cryostat cabinet until used.

\section{Immunohistochemistry}

Cancer cells were detected by using Ulex Europaeus agglutinin I (UEA-1), a selective marker of colon carcinoma cells in rat (Caldero et al., 1989; Griffini et al., 1996). Sections were air-dried and fixed in acetone for $7 \mathrm{~min}$ at $4{ }^{\circ} \mathrm{C}$ and preincubated for $15 \mathrm{~min}$ using $10 \%(\mathrm{v} / \mathrm{v})$ normal goat serum in phosphate-buffered saline (PBS) to block nonspecific binding. Then, sections were incubated for $60 \mathrm{~min}$ using Ulex Europaeus agglutin I (Dakopatts, Glostrup, Denmark) diluted 1:100 in PBS and for 30 min with rabbit anti-Ulex Europaeus Lectin type-1 conjugated with horseradish peroxidase (Dakopatts) diluted 1:50 in PBS in the presence of $10 \% \mathrm{AB}$ serum. Visualization of peroxidase activity was performed by incubation with a solution containing $50 \mathrm{mg}$ 3,3-diaminobenzidine-tetrachloride (DAB; Sigma, St Louis, MO, U.S.A.) dissolved in $100 \mathrm{~mL}$ Tris-HCl buffer (50 mm, $\mathrm{pH} 7 \cdot 6)$ and a final hydrogen peroxide concentration of $0.01 \%$. Sections were rinsed in distilled water, counterstained with haematoxylin and mounted in glycerine-gelatin.

\section{Histochemical procedures}

Basement membranes were stained histochemically using the method of Shoobridge (1983) as described previously (Jonges et al., 1993).

\section{Morphometric 3D analysis}

Twenty-six metastases were analysed in 3D using serial sections. For this purpose, series of 25-150 sections of livers containing metastases were stained alternately with immunohistochemical and histochemical means to detect cancer cells and basement membranes. For each metastasis, 6-12 images were taken consecutively at a magnification of $10 \times$ using an Olympus Vanox T AH-2 photomicroscope and a Splan Apo 10 objective. These images were numbered and mounted as a collage. This procedure allowed us to have a preliminary 3D impression of all metastases for further 3D reconstruction. Special attention was given to the following aspects: distance to the surface of the liver and/or contact with Glisson's capsule, presence of stroma, interactions with blood vessels, differentiation patterns of cancer cells, direction of growth, presence of necrosis, oedema or blood vessels within tumours. Furthermore, the mean apparent diameter $(d)$ of each metastasis was determined using the formula $d=\sqrt{ }\left(1 / 2 a^{2}+1 / 2 b^{2}\right)$ (Martin et al., 1989) where $a$ and $b$ are perpendicular apparent diameters measured with the use of a micrometer mounted in a $\times 10$ ocular at $\times 2.5$ objective magnification.

\section{$3 D$ reconstruction}

Thirty-seven to 110 consecutive serial sections ( $8 \mu \mathrm{m}$ thick) were used for 3D reconstructions of each tumour. Contours of metastases, cancer cells, stroma, blood vessels and Glisson's capsule were manually traced per section with a digitizer tablet and stored in a database (Verbeek et al., 1995). Two reference points were included for each section imported into the input database. These reference points were marked on each drawing on the basis of a fiducial that remained the same throughout the whole series of sections. The reference points in the input database were the basis for realignment (Verbeek et al., 1993; Verbeek, 1995), thus correcting for differences in orientation and position of consecutive sections. The minimal square distance between two consecutive reference points was used as criterion for proper fit. The contour stack in the input database was not aligned. The realignment step of the program transformed this database to an aligned output database. The latter database contained 3D reconstructions of the specimens and it was used for the rendering on a computer screen (Verbeek et al., 1990; Verbeek, 1995). The database represented the number of sections produced by sectioning. However, not all sections were used to produce the 3D reconstructions. The unused sections were represented by discontinuous empty spaces in the rendering phase. Initial rendering was accomplished with a contour model, which is especially useful to find a model orientation that emphasizes the intended structural relationships. At this stage also a subset of all structures was selected for further analysis. A more realistic visualization than the contour model was accomplished by using the volume enumeration model which is also called the voxel model. Therefore, the contour models were used to generate voxel models (Verbeek et al., 1991, 1993; Verbeek, 1995, 1996) of the different stages of 
the metastases. In the voxel model, structures appear as labelled regions (see Fig. 2). The volumetric representations of these regions were used in volume rendering based on the principle of ray-casting (Levoy, 1988; Keller \& Keller, 1993). This visualization technique is common for rendering of (binary) voxel models. It takes into account density, in this case a label and opacity of the voxels. To that end a certain opacity was assigned to specific structures. The ray-casting algorithm computes the screen value of a projection of the volume given the opacity characteristics of the voxels. This projection is the summation of densities and opacity along a ray from the light source to the eye of the (imaginary) viewer. The opacity characteristic was used to make structures translucent so that encapsulated structures could be visualized.

The program for 3D reconstruction was developed in the MS-Windows user interface. It required minimally a 386 PC equipped with a SVGA video adapter and at least $4 \mathrm{Mb}$ of RAM in order to operate properly. A Summagraphics Bitpad Two was used for the input of the contours (Verbeek et al., 1995). The driver software for this digitizer was included in the $3 \mathrm{D}$ reconstruction program.

Conversion of the contour model into the voxel model was realized with a 3D base software module (Verbeek et al., 1993) designed for conversion of one geometrical representation to another, e.g. of a contour representation to a volume representation. The volume renderings were generated with SunVision visualization software (Sun MicroSystems, Amersfoort, The Netherlands) using a SUN SPARC II (64 Mb RAM). The renderings were saved to disk and transferred to a high-resolution slide-writer to obtain highquality hard copies.

\section{Results}

The 26 metastases that were found in livers of five out of eight rats at 3 weeks after intravenous administration of colon cancer cells showed heterogeneity with respect to their location in the liver lobule, size and pattern of growth. Heterogeneity could often be detected in one liver section (Fig. 1).

Seven small metastases (mean diameter \pm standard deviation (SD), $0 \cdot 3 \pm 0 \cdot 1 \mathrm{~mm}$ ) were found and 3D reconstruction revealed that all seven had similar features: (1) cancer cells were totally encapsulated by stroma which was always connected with adjacent portal vessels (Fig. 2A,B); (2) all cancer cells were arranged in well-differentiated acini and surrounded by a continuous basement membrane (Fig. 3); (3) the tumours all grew distant from the liver surface. The shortest distance between metastasis and liver surface varied between 0.7 and $3.6 \mathrm{~mm}$.

The other 19 metastases were larger (mean diameter \pm SD, $1 \cdot 2 \pm 0.4 \mathrm{~mm}$ ) and could be divided into two subgroups: one group contained nine metastases (mean diameter \pm SD,
$0.9 \pm 0.4 \mathrm{~mm}$ ) without necrotic areas (Fig. 2C,D) and the other subgroup contained 10 metastases (mean diameter \pm SD, $1.4 \pm 0.5 \mathrm{~mm}$ ), all containing necrotic areas (Fig. 2E,F). 3D reconstruction showed that all 19 metastases were at least partly in contact with the liver capsule (Fig. 2C-F, 4 and 5). Within one tumour (Fig. 2C-D) or even within one section (Fig. 4) of the first subgroup both acini surrounded by a basement membrane and stroma and regions of undifferentiated cancer cells without surrounding basement membrane and stroma could be found. The metastases of the latter subgroup consisted mainly of undifferentiated cancer cells without continuous surrounding basement membrane in direct contact with hepatocytes (Fig. 5A). Stroma was confined to few areas in the metastases in between and around small clusters of cancer cells only (Fig. 5B). This stroma was always connected with portal tracts. The cancer cells within the clusters were poorly differentiated and never surrounded by a basement membrane (Fig. 5B). Tumours in sections of these areas were difficult to classify because they showed characteristics of both the small (small size, presence of stroma) and larger tumours (the poor differentiation grade of the cancer cells). 3D reconstruction revealed that they were part of the latter category of tumours.

\section{Discussion}

The complexity which is inherent to the development of metastasis in vivo hampers understanding of the essential steps in tumour invasion and metastasis. In particular, the lack of methods for direct observations of the dynamics of tumour invasion in the nontransparent living host tissue limits developments in this aspect. CT, MRI and in vivo microscopy are useful for the detection of tumours and metastases (Walsh \& Goplerud, 1981; Gabbert, 1985; Kim et al., 1990; Bennet et al., 1991; Van Leeuwen et al., 1994, 1995; Kan et al., 1995) and for the follow-up of the response to therapy (Tacek et al., 1991; Hricak et al., 1993), but these techniques are based on the acquisition of noninvasive virtual sections with a spatial resolution of the order of millimetres. Therefore, these techniques do not provide sufficient spatial resolution for detection of micrometastases (Schreve et al., 1984) or interactions between cancer cells, stroma and surrounding tissues. Although recent developments increased spatial resolution of MRI (Kriete \& Pepping, 1992; Jacobs \& Fraser, 1994), it still does not provide details of internal structures. This is due to the fact that MRI imaging is based on a physical principle such as the magnetic moment of hydrogen in water which does not necessarily reflect the anatomy of interest. For imaging of internal structures of an object, the use of physical sections and histochemistry is still required (Verbeek, 1995). Therefore, MRI cannot be considered as the appropriate technique to study spatial and dynamic 


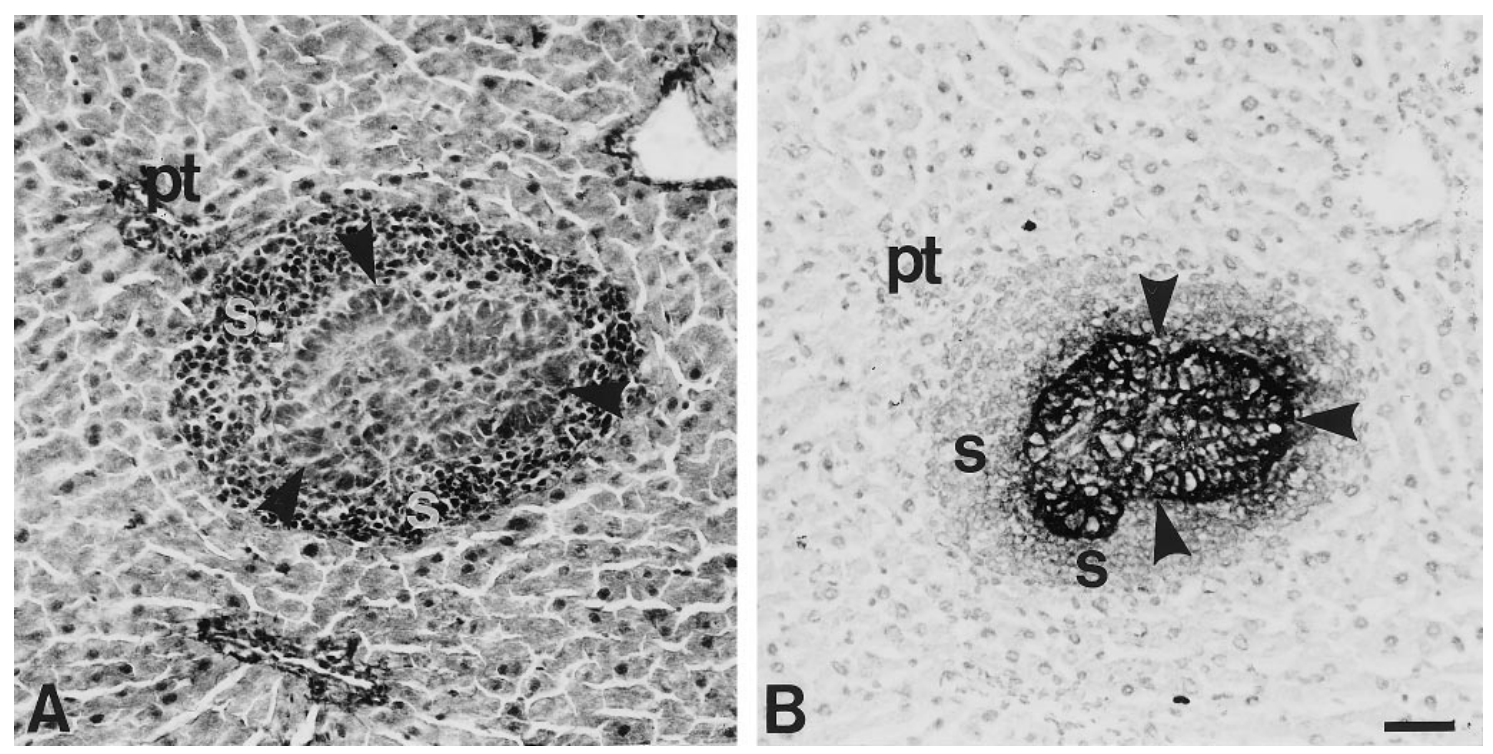

Fig. 3. Serial sections of liver containing the small metastasis shown in 3D in Fig. 2A and B, after staining with the Shoobridge method (A) and with the lectin UAE-I to demonstrate specifically cancer cells (B). The colon cancer cells (arrowheads) were totally surrounded by a basement membrane and stroma (s) connected with a portal tract (pt). Scale bar $=50 \mu \mathrm{m}$.

interactions between cancer cells and surrounding tissues and cells. Physical sections allow a spatial resolution in the range of micrometres. The disadvantage of sectioning is the loss of integrity in the third dimension; therefore, 3D reconstruction from serial sections has been developed to restore initial relations in the object under study (Verbeek, 1995). In recent years, a number of software packages for $3 \mathrm{D}$ reconstruction at the microscopical level have become available (Huijsmans et al., 1986; Verbeek et al., 1990, 1991) and applied to anatomy (Gras, 1984; Mercer et al., 1987; Campbell et al., 1992), developmental biology (Deverell et al., 1993; Salisbury et al., 1993; Verbeek et al., 1995), neurosciences (Mercer et al., 1987; Rydmark et al., 1992), histopathology (Yaegashi \& Takahashi, 1990; Dinges et al., 1992; Zanen et al., 1993) and tumour biology in the present study.

The data of our 3D study showed a dual role of stroma with respect to the growth of colon cancer metastases in rat liver. On the one hand, contact between tumours and the liver capsule is of vital importance for metastases to grow because the 19 large metastases out of 26 metastases studied were found at the surface of the liver in direct contact with Glisson's capsule (Fig. 2C-F). Invasion of Glisson's capsule is a common phenomenon that is still not properly understood. It occurs both in patients with colorectal metastases (Yamamoto et al., 1995) and in experimental animal models (Chauffert et al., 1988; Dingemans et al., 1994). Granulation tissue which is formed when metastases make contact with the liver capsule (Dingemans et al., 1994) seems to favour invasion of tumours (Gabbert, 1985; Pauli \& Knudson, 1988). On the other hand, stroma connected with portal tracts seems to be able to limit invasion of metastases by creating a barrier to the tumours. This was demonstrated by the fact that when stroma was present as a continuous layer around the cancer cells, the metastases remained small which was the case with all seven metastases that were not in contact with the liver capsule (Fig. 2A,B). Furthermore, in the group of larger metastases there was distinctly less stroma surrounding the largest metastases. This is in line with the observations of Vaage (1992) and Nakanishi et al. (1994) who demonstrated in vivo that a cellular-fibrous capsule around the tumour was responsible for tumour dormancy and regression and that tumours induced by low-metastatic cells were characterized by considerable amounts of interstitial stroma in comparison with tumours derived from highly metastatic cells which contained only limited amounts of stroma. The different types of stroma observed, namely stroma rich in cellular elements surrounding cancer cells in small tumours and granulation tissue, rich in extracellular matrix but with fewer cells, in the areas of contact between larger tumours and the liver capsule resemble the earlier and later stages of wound healing, respectively (Dvorak, 1986).

The presence of stroma and in particular of intact basement membranes around cancer cells was always associated with well-differentiated cancer cells organized in acinar patterns and with noninvasiveness of cancer cells into the adjacent liver tissue. Invasion of cancer cells into host tissue was always associated with a lack of a basement membrane and stroma in between cancer cells and liver tissue and with a poorly differentiated growth pattern of 

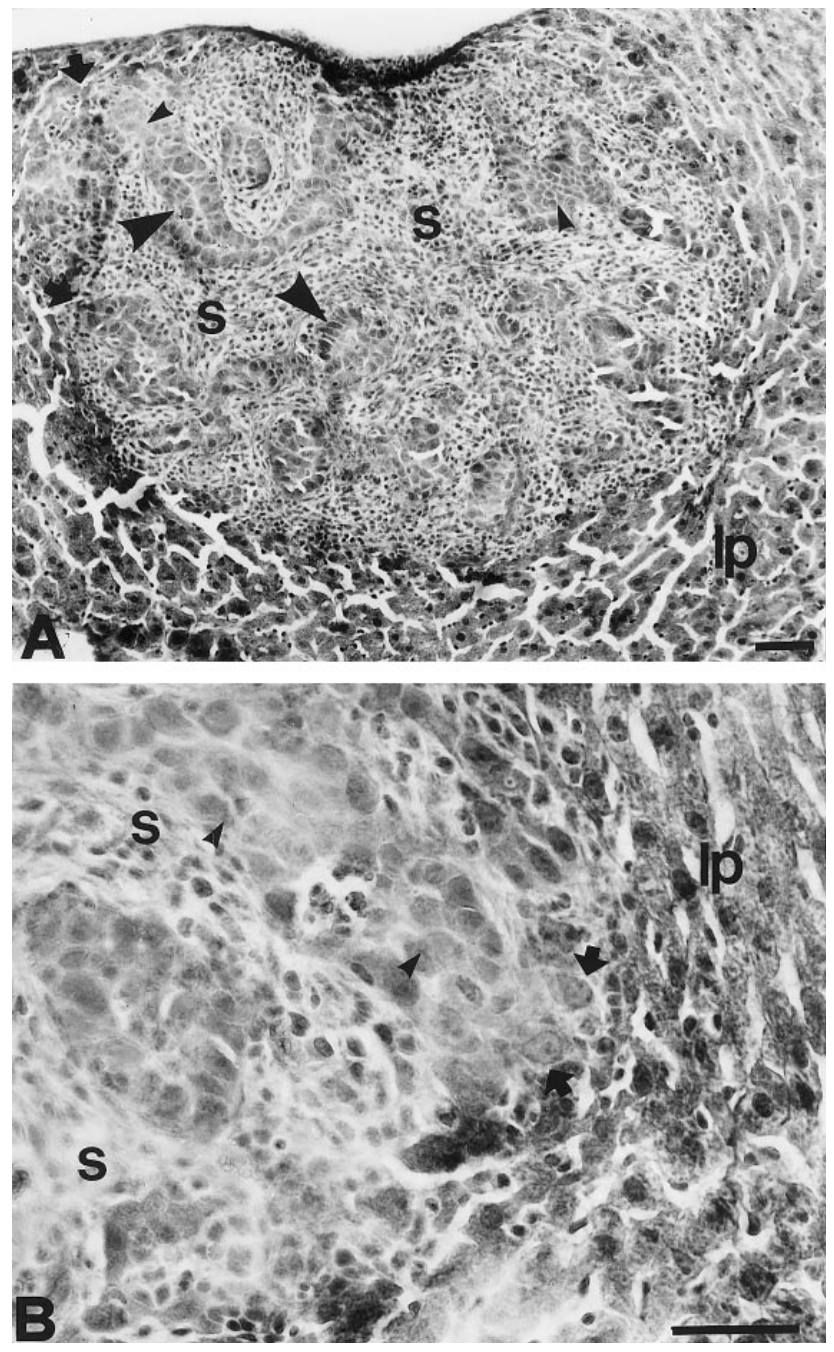

Fig. 4. Low (A) and higher (B) magnification of a section of the metastasis shown in 3D in Fig. 2C and D stained with the Shoobridge method. Both acini of differentiated cancer cells (arrowheads) surrounded by a basement membrane and stroma (s) and regions of undifferentiated cancer cells (small arrowheads) without surrounding basement membrane and stroma but in close contact with liver parenchyma (lp) (arrow) were found in the same section. Scale bar $=50 \mu \mathrm{m}$.

cancer cells. There is evidence that poorly differentiated tumours possess a higher invasiveness and worse prognosis than the differentiated tumours of the same tissue of origin (Thynne et al., 1980; Brawn, 1983) and that there is an inverse relationship between the grade of tumour invasion and the metastatic capacity of a particular tumour (Eccles, 1983; Barnett \& Eccles, 1984). This capacity depends on the production by cancer cells of several classes of proteases, such as metalloproteinases, serine proteinases and cysteine proteinases (Sloane, 1990; Monsky \& Chen, 1993; Mignatti \& Rifkin, 1993) which are responsible for the degradation and loss of basement membrane around cancer cells (Liotta,
1992). It has been demonstrated by Gabbert (1985) that differentiated colon cancer cells arranged in acinar patterns are able to synthesize a continuous basement membrane whereas undifferentiated cancer cells are defective in the synthesis of basement membranes.

Another aspect that is clearly shown by the $3 \mathrm{D}$ analysis is the heterogeneity of tumour-host interactions and of the morphology of a tumour at different sites. Especially in larger metastases, sites of invasive cancer cells and sites of noninvasive acini could be found in one and the same metastasis when analysed in 3D. This heterogeneity was often not apparent when analysing metastases in 2D (Fig. 5). Furthermore, our 3D analysis revealed that invasion of metastases does not occur solely in the direction of the liver capsule. Outgrowth of metastases inwards into liver parenchyma was found frequently as well (Fig. 2). This observation is relevant with respect to surgical removal and has to be taken into consideration in order to avoid the risk of incomplete resection of liver metastases (Yamamoto et al., 1995). In this context there is another important aspect emerging from our 3D observations which is related to the presence of smaller and larger metastases within one liver. An example is shown in Fig. 1. The smaller tumours may well be undetectable by CT or MRI techniques and when this tumour is not completely removed during resection of the larger metastases, it can be responsible for recurrence of metastases.

In conclusion, the present 3D study revealed histological heterogeneity of tumours of colon cancer in liver. 3D reconstruction of tumours provides useful information for the understanding of spatial interactions between cancer cells and host cells that are involved in the development of colon carcinoma metastases in liver. Furthermore, we suggest that $3 \mathrm{D}$ reconstructions from serial sections of colon carcinoma metastases in combination with MRI and/ or spiral CT imaging can be a useful tool in the study of specific aspects of metastases such as angiogenesis and local effects of therapies.

\section{Acknowledgments}

We would like to thank Mrs K. S. Bosch and Mrs I. M. C. Vogels for their technical assistance, Mr J. Peeterse for photographic work, Mr P. J. van Amstel for preparation of the cancer cell line, Mr H. G. Lagerweij for the careful animal experiments, Mrs T. M. S. Pierik for the preparation of the manuscript and C. de Gier and J. Hagoort from the Department of Anatomy and Embryology who assisted setting up the input of the contours. This study was performed in the Department of Cell Biology \& Histology, Academic Medical Centre, University of Amsterdam, as parts of the $\mathrm{PhD}$ and postdoctoral research projects of P. Griffini on a NUFFIC bursary and a CNR bilateral research 
Fig. 5. Sections of liver stained with the lectin UAE-I containing the large metastasis shown in 3D in Fig. 2E and F. (A) This section shows that the tumour was in direct contact with Glisson's capsule (arrowheads) and contained colon cancer cells that were in direct contact (arrows) with liver parenchyma (lp), a central necrotic area (n) and stroma (s) that was connected with a portal tract (pt). (B) This section shows that the tumour was at distance of the capsule (arrowheads) and contained stroma (s) recruited from a portal tract (pt) and infiltrating in between colon cancer cells (arrows). Scale bar $=50 \mu \mathrm{m}$.
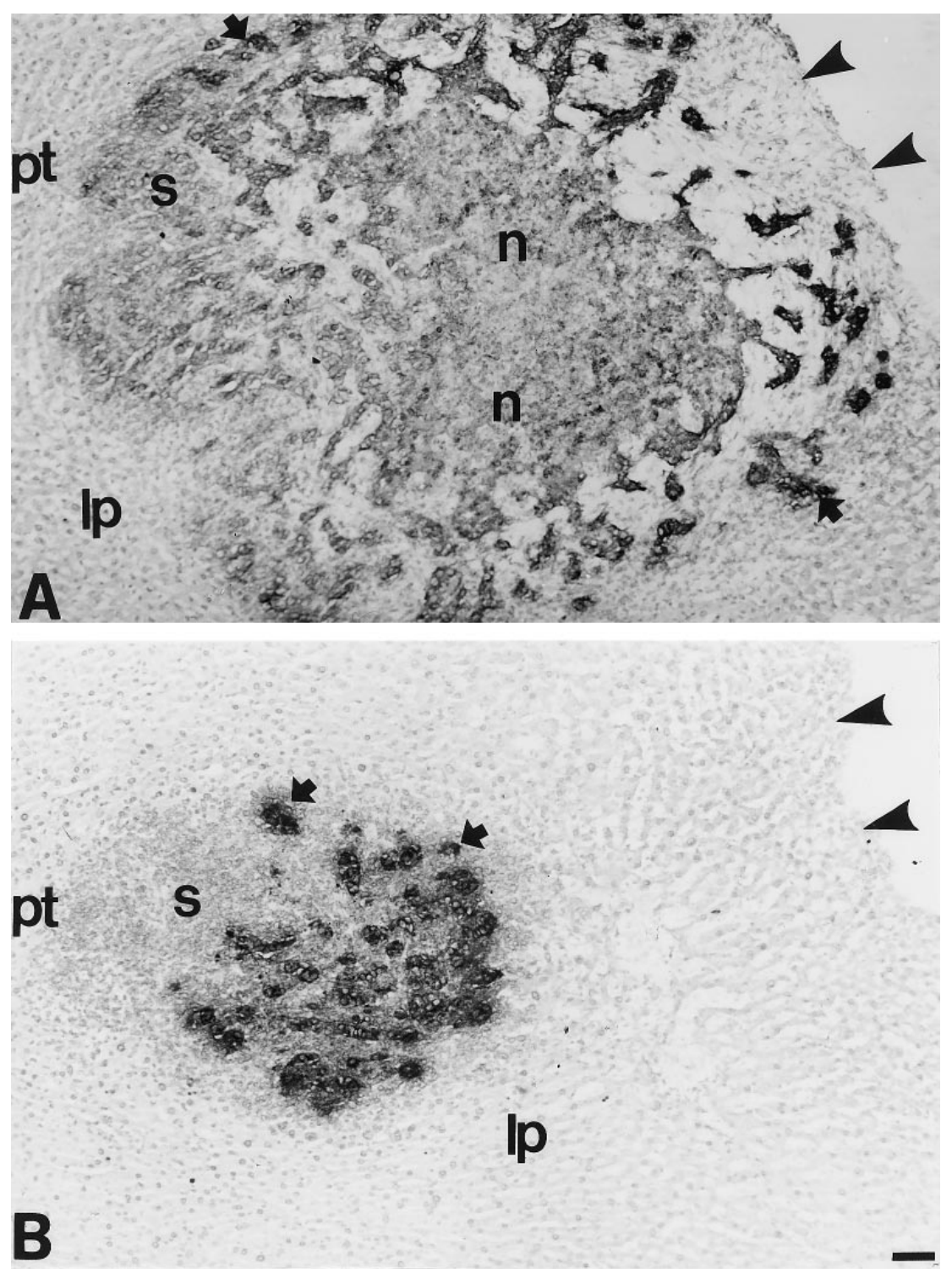

programme between the University of Amsterdam and the University of Pavia.

\section{References}

Adson, M.A., van Heerden, J.A., Adson, M.H., Wagner, J.S. \& Ilstrup, D.M. (1984) Resection of hepatic metastases from colorectal cancer. Arch. Surg. 119, 647-651.

Barberá-Guillem, E., Alonso-Varona, A. \& Vidal-Vanaclocha, F. (1989) Selective implantation and growth in rats and mice of experimental liver metastasis in acinar zone one. Cancer Res. 49, 4003-4010.

Barnett, S.C. \& Eccles, S.A. (1984) Studies of mammary carcinoma metastasis in a mouse model system. I. Derivation and characterization of cells with different metastatic properties during tumour progression in vivo. Clin. Exp. Metast. 2, 15-36.
Bengmark, S., Hafstrom, L., Jeppsson, B., Jonsson, P.E., Ryden, S. \& Sundqvist, K. (1982) Metastatic disease in the liver from colorectal cancer: an appraisal of liver surgery. World J. Surg. 6, 61-65.

Bennet, W.F., Bova, J.G., Petty, L. \& Martin, E.W. (1991) Preoperative 3D rendering of MR imaging in liver metastases. J. Comput. Assist. Tomogr. 15, 989-994.

Brawn, P.N. (1983) The dedifferentiation of prostate carcinoma. Cancer, 52, 246-251.

Caldero, J., Campo, E., Viñas, J. \& Cardesa, A. (1989) Lectinbinding sites in neoplastic and non-neoplastic colonic mucosa of, 1,2-dimethylhydrazine-treated rats. Lab. Invest. 61, 670676.

Campbell, F., Garrahan, N.J., Deverell, M.H., Whimster, W.F. \& Williams, G.T. (1992) Application of a computer aided design system to the three dimensional reconstruction of colonic crypts. J. Pathol. 168, 125A. 
Chauffert, B., Shimizu, T., Caignard, A., Hammann, A., Genne, P., Pelletier, H. \& Martin, M.S. (1988) Use of a specific monoclonal antibody for studying the liver metastatic invasion of a rat colon cancer. In Vivo, 2, 301-306.

Deverell, M.H., Salisbury, J.R., Cookson, M.J., Holman, J.G., Dykes, E. \& Whimster, W.F. (1993) Three dimensional reconstruction: methods of improving image registration and interpretation. Anal. Cell. Pathol. 5, 253-263.

Dingemans, K.P., Van den Bergh Weerman, M.A., Keep, R.F. \& Das, P.K. (1994) Developmental stages in experimental liver metastases: relation to invasiveness. Int. J. Cancer, 57, 433-439.

Dinges, H.P., Zatloukal, K., Denk, H., Smolle, J. \& Mair, S. (1992) Alcoholic liver disease. Parenchyma to stroma relationship in fibrosis and cirrhosis as revealed by three-dimensional reconstruction and immunohistochemistry. Am. J. Pathol. 141, 69-83.

Dvorak, H.F. (1986) Tumors: wounds that do not heal. Similarities between tumor stroma generation and wound healing. New Engl. J. Med. 315, 1650-1659.

Eccles, S.A. (1983) Differentiation and neoplasia. Invasion and metastasis; experimental systems. J. Pathol. 141, 333-353.

Fidler, I.J. \& Balch, C.M. (1987) The biology of cancer metastases and implications for therapy. Curr. Probl. Surg. 24, 129-209.

Fidler, I.J. \& Hart, I.R. (1982) Biological diversity in metastatic neoplasms: origins and implications. Science, 217, 998-1003.

Fortner, J.G., Silva, J.S. Cox, E.B., Golbey, R.B., Gallowitz, H. \& Maclean, B.J. (1984) Multi-variate analysis of a personal series of 247 consecutive patients with liver metastases from colorectal cancer. Ann. Surg. 199, 306-316.

Gabbert, H. (1985) Mechanism of tumor invasion: evidence from in vivo observations. Cancer Metast. Rev. 4, 293-309.

Gras, H.A. (1984) A 'hidden' line algorithm for 3D-reconstruction from serial sections - an extension of the NEUREC program package for a microcomputer. Comput. Progr. Biomed. 18, 217-226.

Griffini, P., Freitas, I., Vigorelli, E. \& Van Noorden, C.J.F. (1994) Changes in the zonation of lactate dehydrogenase activity in lobules of rat liver after experimentally induced colon carcinoma metastases. Anticancer Res. 14, 2537-2540.

Griffini, P., Smorenburg, S.M., Vogels, I.M.C., Tigchelaar, W. \& Van Noorden, C.J.F. (1996) Kupffer cells and pit cells are not effective in the defence against experimentally induced colon carcinoma metastasis in rat liver. Clin. Exp. Metast. 14, 367-380.

Hricak, H., Quivey, J.M., Campos, Z., Gildengorin, V., Hindmarsh, J., Bis, K.G., Stern, J.L. \& Philips, T.L. (1993) Carcinoma of the cervix: prediction in value of clinical or MR imaging assessment of prognostic factors. Int. J. Radiat. Oncol. Biol. Phys. 27, 791-801.

Hughes, K.S., Rosenstein, R.B., Songhorabodi, S., Adson, M.A., Ilstrup, D.M., Fortner, J.G., MacLean, B.J., Foster, J.H., Daly, J.M. \& Fitzherbert, D. (1988) Resection of the liver for colorectal carcinoma metastases: a multiinstitutional study of long-term survivors. Dis. Colon Rectum, 31, 1-4.

Hughes, K., Scheele, J. \& Sugarbakker, P.H. (1989) Surgery for colorectal cancer metastatic to the liver. Optimizing the results for treatment. Surg. Clin. North Am. 69, 339-359.

Huijsmans, D.P., Lamers, W.H., Los, J.A. \& Strackee, J. (1986) Toward computerized morphometric facilities: a review of 58 software packages for computer-aided 3D reconstruction, quantification and picture generation from parallel serial sections. Anat. Rec. 216, 449-470.

Jacobs, R.E. \& Fraser, S.E. (1994) Magnetic resonance microscopy of embryonic cell-lineages. Science, 263, 681-684.

Jonges, G.N., Vogels, I.M.C., Bosch, K.S., Dingemans, K.P. \& Van Noorden, C.J.F. (1993) Experimentally induced colon cancer metastases in rat liver increase the proliferation rate and capacity for purine catabolism in liver cells. Histochemistry, 100, 41-51.

Kan, Z., Ivancev, K., Lunderquist, A., McCuskey, P.A., McCuskey, R.S. \& Wallace, S. (1995) In vivo microscopy of hepatic metastases: dynamic observation of tumor cell invasion and interaction with Kupffer cells. Hepatology, 21, 487-494.

Keller, P.R. \& Keller, M.M. (1993) Visual Cues, Practical Data Visualization. IEEE Computer Society Press, Los Alamalitos.

Kim, S.H., Choi, B.I. \& Lee, H.P. (1990) Uterine cervical carcinoma: comparison of CT and MR findings. Radiology, 175, 45-51.

Kriete, A. \& Pepping, T. (1992) Volumetric data representations in microscopy: applications to confocal and NMR-microimaging. Visualisation in Biomedical Microscopy (ed. by A. Kriete), pp. 329-359. VCH Weinheim.

Levoy, M. (1988) Display of surfaces from volume data. IEEE Comp. Graph. Appl. 8, 29-37.

Liotta, L.A. (1992) Cancer cell invasion and metastasis. Sci. Am. 269, 34-41.

Liotta, L.A., Steeg, P.S. \& Stetler-Stevenson, W.G. (1991) Cancer metastasis and angiogenesis: an imbalance of positive and negative regulation. Cell, 64, 327-336.

Lise, M., Da Pian, P.P., Nitti, D., Pilati, P.L. \& Prevaldi, C. (1990) Colorectal metastases to the liver: present status of management. Dis. Colon Rectum, 8, 688-694.

Mareel, M.M., Van Roy, F.M. \& De Baetselier, P. (1990) The invasive phenotypes. Cancer Metast. Rev. 9, 45-62.

Marquet, R.L., Westbroek, D.L. \& Jeekel, J. (1984) Interferon treatment of transplantable rat colon adenocarcinoma: importance of tumor site. Int. J. Cancer, 33, 689-692.

Martin, M., Chauffert, B., Caignard, A., Pelletier, H., Hammann, A. \& Martin, F. (1989) Histoimmunological characterization of the cellular reaction to liver metastases induced by colon cancer cells in syngeneic rats. Invasion Metast. 9, 216-230.

Mercer, R.R., Laco, J.M. \& Crapo, J.D. (1987) Three-dimensional reconstruction of alveoli in the rat lung for pressure-volume relationships. J. Appl. Physiol. 62, 1480-1487.

Mignatti, P. \& Rifkin, D.B. (1993) Biology and biochemistry of proteinases in tumor invasion. Physiol. Rev. 73, 161-195.

Minton, J.P., Hamilton, W.P., Sardi, A., Nieroda, C., Sickle-Santanello, B. \& O'Dwyer, P.J. (1989) Results of surgical excision of one to 13 hepatic metastases in 98 consecutive patients. Arch. Surg. 124, 46-48.

Monsky, W.L. \& Chen, W.T. (1993) Proteases of cell adhesion proteins in cancer. Semin. Cancer Biol. 4, 251-258.

Nakanishi, H., Oguri, K., Takenaga, K., Hosoda, S. \& Okayama, M. (1994) Differential fibrotic stromal responses of host tissue to low- and high-metastatic cloned Lewis lung carcinoma cells. Lab. Invest. 70, 324-332.

Nicolson, G.L. (1987) Tumor cell instability, diversification and progression to the metastatic phenotype: from oncogene to oncofetal expression. Cancer Res. 47, 1473-1487. 
Nitti, D., Civalleri, D., Samori, G., Bachi, V., Dapian, P.P., Labianca, R., Pancera, G., Lise, M., Panvini, D., Tinazzi, A., Torri, V. \& Marsoni, S. (1994) Retrospective study on adjuvant chemotherapy after surgical resection of colorectal cancer metastatic to the liver. Eur. J. Surg. Onc. 20, 454-460.

Panis, Y., Ribeiro, J., Chrétien, Y. \& Nordlinger, B. (1992) Dormant liver metastases: experimental study. Br. J. Surg. 79, 221-223.

Pauli, B.U. \& Knudson, W. (1988) Tumor invasion: a consequence of destructive and compositional matrix alterations. Hum. Pathol. 19, 628-639.

Pedersen, I.K., Burcharth, F., Roikjaer, O. \& Baden, H. (1994) Resection of liver metastases from colorectal cancer. Dis. Colon Rectum, 37, 1078-1082.

Rydmark, M., Jansson, T., Berthold, C.H. \& Gustavsson, T. (1992) Computer-assisted realignment of light micrograph images in consecutive section series of rat cerebral cortex. J. Microsc. 165, $29-47$.

Salisbury, J.R., Deverell, M.H., Cookson, M.J. \& Whimster, W.F. (1993) Three-dimensional reconstruction of human embryonic notochords. Clue to the pathogenesis of chordoma. J. Pathol. 171, 59-62.

Schreve, R.H., Terpstra, O.T., Ausema, L., Lameris, J.S., Van Seijn, A.J. \& Jeekel, J. (1984) Detection of liver metastases. A prospective study comparing liver enzymes, scintigraphy, ultrasonography and computed tomography. Br. J. Surg. 71, 947-949.

Shoobridge, M.P.K. (1983) A new principle in polychrome staining; a system of automatic staining, complementary to haematoxylin and eosin, and usable as a research tool. Stain Technol. 58, 245-258.

Sloane, B.F. (1990) Cathepsin B and cystatins: evidence for a role in cancer progression. Semin. Cancer Biol. 1, 137-152.

Smorenburg, S.M., Griffini, P., Tiggelman, A.M.B.C., Moorman, A.F.M., Boers, W.M. \& Van Noorden, C.J.F. (1996) $\alpha 2$-macroglobulin is mainly produced by cancer cells and not by hepatocytes in rats with colon carcinoma metastases in liver. Hepatology, 23, 560-570.

Tacek, T., Strnad, V., Vacek, O., Rasovska, B., Prokes, E., Ptackova, E. \& Krystof, V. (1991) Radiotherapy of cervix uterine carcinoma with Cf-252 implant and external hypoxy-radiotherapy. Nucl. Sci. Appl. 4, 201-212.

Thynne, G.S., Weiland, L.H., Moertel, C.G. \& Silvers, A. (1980) Correlation of histopathologic characteristics of primary tumor and uninvolved regional lymph nodes in Dukes Class C colonic carcinoma with prognosis. Mayo Clin. Proc. 55, 243-245.

Vaage, J. (1992) Fibrosis in immune control of mammary-tumor growth. Int. J. Cancer, 51, 325-328.

Van Leeuwen, M.S., Noordzij, J., Fernandez, M.A., Hennipman, A.H.,
Feldberg, M.A.M. \& Dillon, E.H. (1994) Observations based on three-dimensional spiral CT renderings. Am. J. Roentgenol. 163, 1395-1404.

Van Leeuwen, M.S., Obertop, H., Hennipman, A.H. \& Fernandez, M.A. (1995) 3D reconstruction of hepatic neoplasms: a preoperative planning procedure. Baillieres Clin. Gastroenterol. 9, 121-133.

Verbeek, F.J. (1995) Three-dimensional reconstruction of biological objects from serial sections including deformation correction. $\mathrm{PhD}$ thesis, University of Technology, Delft, The Netherlands.

Verbeek, F.J. (1996) 3D reconstruction from serial sections: applications and limitations. Microsc. Anal. (UK), 44, 33-35.

Verbeek, F.J., De Groot, M.M. \& Huijsmans, D.P. (1991) 3D-Base: database description for 3D shape exchange. Cytometry (Suppl.) 5, 124.

Verbeek, F.J., De Groot, M.M., Huijsmans, D.P., Lamers, W.H. \& Young, I.T. (1993) 3D BASE: a geometrical database system for the analysis and visualisation of 3D shapes obtained from parallel serial sections including three different geometrical representations. Comp. Med. Imag. Graph. 17, 151-163.

Verbeek, F.J., Huijsmans, D.P., Baeten, R.J.A.M., Schoutsen, N.J.C. \& Lamers, W.H. (1995) Design and implementation of a database and program for 3D reconstruction from serial sections: a datadriven approach. Microsc. Res. Tech. 30, 496-512.

Verbeek, F.J., Schoutsen, N.J.C. \& Huijsmans, D.P. (1990) A PCbased package for three-dimensional reconstruction of microscopical objects. Cytometry (Suppl.) 4, 105.

Wagner, J.S., Adson, M.A., Van Heerden, J.A., Adson, H. \& Ilstrup, D.M. (1984) The natural history of hepatic metastases from colorectal cancer. Ann. Surg. 199, 502-508.

Walsh, J.W. \& Goplerud, D.R. (1981) Prospective comparison between clinical and CT staging in primary cervical carcinoma. Am. J. Roentgenol. 137, 997-1003.

Yaegashi, H. \& Takahashi, T. (1990) Encasement and other deformations of tumor-embedded host arteries due to loss of medial smooth muscles. Morphometric and three-dimensional reconstruction studies on human carcinomas. Cancer, 65, 1097-1103.

Yamamoto, J., Sugihara, K., Kosuge, T., Takayama, T., Shimada, K., Yamasaki, S., Sakamoto, M. \& Hirohashi, S. (1995) Pathologic support for limited hepatectomy in the treatment of liver metastases from colorectal cancer. Ann. Surg. 221, 74-78.

Zanen, J., Carinci, V., Nonclercq, D., Toubeau, G., Laurent, G. \& Heuson-Stiennon, J.A. (1993) Morphometric and tridimensional studies of tubular cystic degeneration in rat kidney following exposure to cisplatin. Anal. Cell. Pathol. 5, 353-366. 